\title{
Fuzzy Multi-Attribute Decision Making Method of Energy Alter- native Evaluation
}

\author{
HaoJing Wang, Chen Fang, and Yu Zhang \\ Electric Power Research Institute, State Grid Shanghai Municipal Electric Power Company, 200437 Shanghai, China
}

\begin{abstract}
It's important to make the suitable energy alternatives with the comprehensive technical and economic indicators for energy-saving, emissions reduction and energy comprehensive utilization under the condition of the optimal comprehensive technology and economy index. A new fuzzy multi-attribute decision making method based on expectation is proposed to construct optimal evaluation index system for electric energy alternatives in the case that the weight information is completely unknown or only partially available. The quantitative analysis of attribute value is carried out, and the weight of each layer in the index system is determined by weighting and comparing with each other. Then, the optimization of power alternatives is achieved. The simulation results prove that the proposed method can not only make full use of the objective fuzzy information, but also achieve the interests of all parties with the advantages of practicability, efficiency and easy operation.
\end{abstract}

\section{Introduction}

With the rapidly development of the economy and the continuous optimization of the industrial structure, the demand for energy is increasing rapidly. However, the traditional energy consumes a lot of resources and generates a lot of pollution, which makes economic development face the restraint of insufficient resources and environmental degradation [1-2]. Electricity, as a secondary energy source, the photovoltaic hybrid energy system is used in photovoltaic green electricity generation mode, and the proportion in the terminal energy source is promoted. The photovoltaic hybrid energy system will help to further enhance the energy utilization ratio in the energy end, reduce environmental pollution, and play an important role in social sustainable development [3].

Determining the overall evaluation plan, achieving quantitative comparison and evaluation of photovoltaic hybrid energy system based on the optimal comprehensive indicators of technical and economic, will not only plays a key role in the actual operation and development for electric power enterprise, but also has far-reaching effects on energy saving and energy comprehensive utilization[4]. At present, domestic and foreign scholars have proposed a few research results in the demand forecasting and scheme evaluation. However, the attention of present study mainly focuses on the demand forecasting and potential analysis. There are few researches on the quantitative evaluation of the photovoltaic hybrid energy system.

In this paper, a fuzzy multi-attribute decision making method of energy alternative evaluation is proposed. The evaluation of photovoltaic hybrid energy system is regarded as a multi-attribute fuzzy decision making problem. The direct fuzzy coefficient can effectively solve the problem that the decision makers are always fuzzy and uncertain, and quantify and select the property of the overall evaluation plan. The cases show that the method is effectively and accurately evaluates the photovoltaic hybrid energy system, when the weight information of the evaluation scheme is completely unknown or only some weight information is known.

\section{Fuzzy multi-attribute decision making method for photovoltaic hybrid energy system}

\subsection{Analysis of factors of photovoltaic hybrid energy system}

In 2015, China proposed to promote the photovoltaic hybrid energy system. In 2016, the State Grid's provincial companies expanded the photovoltaic hybrid energy market, and the sale volume maintained a positive growth. The quantitative comparison methods for comparison and selection of the photovoltaic hybrid energy system have played an essential role. This paper selected four key factors of the system: quality attribute (C1), economic attribute $(\mathrm{C} 2)$, technical attribute $(\mathrm{C} 3)$, environmental attribute (C4), to quantitatively analyze the system. Each key factor also contains a number of specific evaluation indexes as shown in Table 1.

Table 1. Linguistic items and equivalent intuitionistic fuzzy numbers 


\begin{tabular}{|c|c|}
\hline $\begin{array}{l}\text { Evaluation } \\
\text { standard }\end{array}$ & Evaluation index \\
\hline \multirow{2}{*}{$\begin{array}{c}\text { Quality } \\
\text { attribute }(\mathrm{C} 1)\end{array}$} & Electric energy supply quality $\mathrm{C} 11$ \\
\hline & Power supply reliability $\mathrm{C} 12$ \\
\hline \multirow{3}{*}{$\begin{array}{c}\text { Economic } \\
\text { attribute }(\mathrm{C} 2)\end{array}$} & $\begin{array}{l}\text { Construction and maintenance and } \\
\text { cost } \mathrm{C} 21\end{array}$ \\
\hline & Government supporting fund C22 \\
\hline & Economic benefit $\mathrm{C} 23$ \\
\hline \multirow{3}{*}{$\begin{array}{c}\text { Technical } \\
\text { attribute(C3) }\end{array}$} & Technical feasibility C31 \\
\hline & Time-to-build C32 \\
\hline & Local construction technology C33 \\
\hline \multirow{3}{*}{$\begin{array}{l}\text { Environmental } \\
\text { attribute(C4) }\end{array}$} & Discharge pollutant C41 \\
\hline & Discharge solid waste C42 \\
\hline & Land demand C43 \\
\hline
\end{tabular}

The detail of the evaluation indexes are as follows:

(1) Quality attributes

C11 reflects the equipment power quality of the photovoltaic hybrid energy system, including the possible error of voltage harmonics, frequency errors, and amplitude.C12 reflects the power supply reliability of the photovoltaic hybrid energy system.

(2) Economic attributes

$\mathrm{C} 21$ reflects the construction cost and maintenance cost of the photovoltaic hybrid energy system and analyzes the total investment of the system. C22 assesses the national and government's economic support. C23 reflects the cost difference of the energy paid by the enterprise between before and after the construction of the photovoltaic hybrid energy system.

(3) Technical attributes

C31 measures the technical feasibility of implementing the photovoltaic hybrid energy system, which can be measured by the number of successful technical tests. C32 reflects the preparation time and the construction time of the system. The C33 standardly assesses the complexity of the technology and the local construction technology and makes the qualitative comparisons to ensure proper operational support for technical maintenance and installation of the photovoltaic hybrid energy system.

(4) Environmental attributes

C41 measures carbon dioxide emissions, gaseous pollutants from combustion and liquid wastes which associated with flue gas treatment or processes. Because the pollutants may will be directly discharged into the nearby environment and cause environmental damage, the evaluation standard include the type and numbers of the emissions and the costs about waste treatment. C42 measures the solid waste that are generated by the photovoltaic hybrid energy system, including equipment damage or scrapping. The evaluation standard includes the amount of solid waste and the cost of treatment. C43 evaluated the land demand of the photovoltaic hybrid energy system, including the area of the equipment and the area for the landfill of solid waste. The higher land demand will increase the investment and also affect area demand of the photovoltaic hybrid energy system.

\subsection{Evaluation method based on fuzzy multi- attribute decision making}

The evaluation of the photovoltaic hybrid energy system is a multi-attribute evaluation problem, which is affected by various factors. It is important for the decision makers to make a subjective judgment under the condition of the current operational practices. This paper proposed a method that the decision makers use the intuitionistic fuzzy numbers to represent the subjective evaluation and replaced the fuzziness and uncertainty of the decision makers. Table 2 shows the linguistic items and its corresponding intuitionistic fuzzy numbers that are used for qualitatively evaluating the given attributes of the photovoltaic hybrid energy system.

Table 2. Linguistic items and equivalent intuitionistic fuzzy numbers

\begin{tabular}{|c|c|}
\hline Linguistic items & $\begin{array}{c}\text { Intuitionistic fuzzy } \\
\text { numbers (membership } \\
\text { degree, non-membership } \\
\text { degree) }\end{array}$ \\
\hline (Very poor) VP & $(0.02,0.98)$ \\
\hline ( Poor) P & $(0.15,0.75)$ \\
\hline (Middle poor) MP & $(0.35,0.55)$ \\
\hline (Fair)F & $(0.50,0.35)$ \\
\hline (Middle good)MG & $(0.65,0.25)$ \\
\hline (Good)G & $(0.75,0.15)$ \\
\hline (Very good)VG & $(0.98,0.02)$ \\
\hline
\end{tabular}

The decision makers' evaluation of a certain attribute of the photovoltaic hybrid energy system involves complex factors, which results the decision makers having a certain degree of hesitation. For example, the decision makers' evaluation of system scheme is "poor", the membership degree is 0.15 , and the non-membership degree is 0.75 . There is uncertainty of 0.1 , which is the degree of hesitation for decision makers.

Based on the determined linguistic items and the corresponding intuitionistic fuzzy numbers, the fuzzy multi-attribute decision making method of energy alternative evaluation is designed, which mainly consists of the following steps:

Step 1: For the problems, define $\boldsymbol{A}=\left\{A_{1}, A_{2}, \ldots A_{n}\right\}$ to represents a set of alternative scheme, and define $\boldsymbol{C}=\left\{C_{l}, C_{2}, \ldots C_{m}\right\}$ to represents a set of attributes, then the decision matrix $\mathrm{D}$ is constructed as:

$$
D=\left[k_{i j}\right]_{m \times n}
$$

Where, $\boldsymbol{k}_{i j}$ is the intuitionistic fuzzy value, $\boldsymbol{k}_{i j}=\left(\boldsymbol{\mu}_{i j}, \boldsymbol{v}_{i j}\right)$. The $\boldsymbol{\mu}_{i j}$ and $\boldsymbol{v}_{i j}$ are represent the degree of satisfaction (membership degree) and dissatisfaction (nonmembership degree) of the $\boldsymbol{C}_{\boldsymbol{i}}$ attribute in the $\boldsymbol{A}_{\boldsymbol{j}}$ scheme.

Define the hesitant index $\boldsymbol{\pi}_{i j}$, which can be represented the ambiguity of the decision makers' judgment on the $\boldsymbol{C}_{\boldsymbol{i}}$ attribute in the $\boldsymbol{A}_{\boldsymbol{j}}$ scheme. The calculation of $\boldsymbol{\pi}_{i j}$ is:

$$
\pi_{i j}=1-\mu_{i j}-v_{i j}
$$

Step 2: Calculate attribute weights 
Using the intuitionistic fuzzy entropy to obtain the weight matrix $\boldsymbol{w}=\left(\boldsymbol{w}_{1}, \boldsymbol{w}_{2}, \ldots, \boldsymbol{w}_{\boldsymbol{m}}\right)$. Where, $\boldsymbol{w}_{i} \geq 0$ and $\sum_{i=1}^{m} w_{i}=1$ The calculation of $\boldsymbol{w}_{\boldsymbol{i}}$ is:

$$
w_{i}=\frac{1}{(m-T)} \times\left(1-a_{i}\right), i=1,2, \ldots, m .
$$

Where,

$$
\begin{gathered}
T=\sum_{i=1}^{m} a_{i} \\
a_{i}=\sum_{j=1}^{n} h_{i j}
\end{gathered}
$$

Where, $\boldsymbol{h}_{i j}$ is the normalized entropy value, the calculation method is as shown in equation (6).

$$
h_{i j}=\frac{E_{i j}}{\max \left(E_{i j}\right)}
$$

In the formula, the max function presents the maximum value of all elements in the entire intuitionistic fuzzy entropy matrix, and $\boldsymbol{E}$ is the intuitionistic fuzzy entropy matrix. The calculation method is:

$$
E_{i j}=\frac{\min \left(\mu_{i j}, v_{i j}\right)+\pi_{i j}}{\max \left(\mu_{i j}, v_{i j}\right)+\pi_{i j}}
$$

Step 3: Establish a weighted intuitionistic fuzzy matrix:

$$
\hat{R}=\left[\hat{x}_{i j}\right]_{m \times n}
$$

Where,

$$
\hat{x}_{i j}=w_{i} x_{i j}=\left[1-\left(1-\mu_{i j}\right)^{w_{i}},\left(v_{i j}\right)^{w_{i}}\right]
$$

Step 4: The determination of the intuitionistic fuzzy positive ideal solution and the intuitive fuzzy negative ideal solution were designed by defining the advantage property $\boldsymbol{\delta}_{1}$ and the cost attribute property $\boldsymbol{\delta}_{2}$. And $\boldsymbol{\varphi}^{+}$is the intuitionistic fuzzy positive ideal scheme, $\varphi^{-}$is the intuitionistic fuzzy negative ideal scheme, there have the formula:

$$
\begin{gathered}
\phi_{C_{i}^{+}}^{+}=\left[\mu_{\phi_{i}^{+}}\left(C_{i}\right), v_{\phi_{i}^{+}}\left(C_{i}\right)\right] \\
\phi_{C_{i}^{-}}^{-}=\left[\mu_{\phi_{i}^{-}}\left(C_{i}\right), v_{\phi_{i}^{-}}\left(C_{i}\right)\right]
\end{gathered}
$$

Where,

$$
\begin{aligned}
& \mu_{\phi_{i}^{+}}\left(C_{i}\right)=\left[\left(\max _{i} \hat{\mu}_{x_{i j}}\left(C_{i}\right) \mid i \in \delta_{1}\right)\left(\min _{i} \hat{\mu}_{x_{i j}}\left(C_{i}\right) \mid i \in \delta_{2}\right)\right] \\
& v_{\phi_{i}^{+}}\left(C_{i}\right)=\left[\left(\min _{i} \hat{v}_{x_{i j}}\left(C_{i}\right) \mid i \in \delta_{1}\right)\left(\max _{i} \hat{v}_{x_{i j}}\left(C_{i}\right) \mid i \in \delta_{2}\right)\right] \\
& \mu_{\phi_{i}^{-}}\left(C_{i}\right)=\left[\left(\min _{i} \hat{\mu}_{x_{i j}}\left(C_{i}\right) \mid i \in \delta_{1}\right)\left(\max _{i} \hat{\mu}_{x_{i j}}\left(C_{i}\right) \mid i \in \delta_{2}\right)\right] \\
& v_{\phi_{i}^{-}}\left(C_{i}\right)=\left[\left(\max _{i} \hat{v}_{x_{i j}}\left(C_{i}\right) \mid i \in \delta_{1}\right)\left(\min _{i} \hat{v}_{x_{i j}}\left(C_{i}\right) \mid i \in \delta_{2}\right)\right]
\end{aligned}
$$

Step 5: Calculate the distance $\boldsymbol{d}_{j}{ }^{+}$of each alternative $\boldsymbol{A}_{j}$ from the intuitionistic fuzzy positive ideal scheme and the distance $\boldsymbol{d}_{\boldsymbol{j}}^{-}$of each alternative $\boldsymbol{A}_{j}$ from the intuitionistic fuzzy negative ideal scheme. Using the fuzzy normalized Euclidean distance to represent the distance between the alternative to the intuitionistic fuzzy positive ideal scheme and the intuitionistic fuzzy negative ideal scheme. The calculation methods of $\boldsymbol{d}_{j}^{+}$and $\boldsymbol{d}_{j}^{-}$are:

$$
d_{j}^{+}=\left\{\frac{1}{2 m} \sum_{i=1}^{m}\left[\left(\hat{\mu}_{i j}\left(C_{i}\right)-\mu_{\phi_{i}^{+}}\left(C_{i}\right)\right)^{2}+\left(\hat{v}_{i j}\left(C_{i}\right)-v_{\phi_{j}^{+}}\left(C_{i}\right)\right)^{2}\right]\right\}^{1 / 2}
$$

$$
d_{j}^{-}=\left\{\frac{1}{2 m} \sum_{i=1}^{m}\left[\left(\hat{\mu}_{i j}\left(C_{i}\right)-\mu_{\phi_{j}^{-}}\left(C_{i}\right)\right)^{2}+\left(\hat{v}_{i j}\left(C_{j}\right)-v_{\phi_{j}^{-}}\left(C_{i}\right)\right)^{2}\right]\right\}^{1 / 2}
$$

Step 6: Calculate the intimacy coefficient $\boldsymbol{C} \boldsymbol{C}_{\boldsymbol{j}}$ of the $\boldsymbol{d}_{j}^{+}$and the $\boldsymbol{d}_{j}^{-}$of each alternative $\boldsymbol{A}_{\boldsymbol{j}}$. The calculation method is:

$$
C C_{j}=\frac{d_{j}^{-}}{d_{j}^{+}+d_{j}^{-}}
$$

Step 7: Sort the alternative $\boldsymbol{A}_{\boldsymbol{j}}(\boldsymbol{j}=1,2, \ldots, \mathrm{n})$ according to the intimacy coefficient $\boldsymbol{C} \boldsymbol{C}_{j}(\boldsymbol{j}=1,2, \ldots \mathrm{n})$. The larger the intimacy coefficient $\boldsymbol{C}_{\boldsymbol{j}}$ is, the alternative $\boldsymbol{A}_{\boldsymbol{j}}$ is getting closer to the optimal solution.

\section{Case analysis}

This paper selects four hybrid energy systems for evaluation, including the energy consumed in the enterprise taken from the photovoltaic hybrid energy system (A1); the photovoltaic generation system is installed in the enterprise and the power grid jointly provide energy for the enterprise (A2); Some energyconsuming equipment in the enterprise are powered by the grid, and others are powered by the photovoltaic hybrid energy system (A3); the wind power generation system is installed in the enterprise, the enterprise is powered by the power grid and the wind power generation system (A4).

The evaluation process of the program is mainly divided into the following steps:

(1) The decision maker first evaluates the relevant attributes of the hybrid energy system program. For a given attribute, the intuitionistic fuzzy numbers for each alternative can be determined from the information shown in Table 2. Table 3 is the qualitative evaluation linguistic terms of each attribute of the mixed energy system plan obtained by integrating each evaluation index.

(2) According to formulas (1)-(7), the entropy of the intuitionistic fuzzy set is used to calculate the weights of each attribute of the photovoltaic hybrid energy system scheme. The weights of each attribute are calculated as:

$$
\begin{aligned}
& w_{1}=0.0314, \\
& w_{2}=0.4308, \\
& w_{3}=0.3947, \\
& w_{4}=0.1431 .
\end{aligned}
$$


(3) According to formulas (8) and (9), the weighted intuitionistic fuzzy decision matrix can be achieved. The calculation results are shown in Table 4.

Table 3. The qualitative evaluation of energy alternatives

\begin{tabular}{|c|c|c|c|c|}
\hline \multirow{2}{*}{$\begin{array}{c}\text { Hybrid } \\
\text { energy } \\
\text { system }\end{array}$} & \multicolumn{4}{|c|}{ Evaluation standard } \\
\cline { 2 - 5 } & $\mathrm{C} 1$ & $\mathrm{C} 2$ & $\mathrm{C} 3$ & $\mathrm{C} 4$ \\
\hline $\mathrm{A} 1$ & $\mathrm{VG}$ & $\mathrm{F}$ & $\mathrm{G}$ & $\mathrm{VG}$ \\
\hline $\mathrm{A} 2$ & $\mathrm{G}$ & $\mathrm{F}$ & $\mathrm{MP}$ & $\mathrm{G}$ \\
\hline $\mathrm{A} 3$ & $\mathrm{G}$ & $\mathrm{G}$ & $\mathrm{F}$ & $\mathrm{G}$ \\
\hline $\mathrm{A} 4$ & $\mathrm{G}$ & $\mathrm{F}$ & $\mathrm{MP}$ & $\mathrm{F}$ \\
\hline
\end{tabular}

Table 4. The weighted intuitionistic fuzzy decision matrix

\begin{tabular}{|c|c|c|c|c|}
\hline & \multicolumn{4}{|c|}{ Property } \\
\cline { 2 - 5 } & $\mathrm{C} 1$ & $\mathrm{C} 2$ & $\mathrm{C} 3$ & $\mathrm{C} 4$ \\
\hline \multirow{2}{*}{$\mathrm{A} 1$} & $(0.115$, & $(0.258$, & $(0.421$, & $(0.428$, \\
& $0.884)$ & $0.636)$ & $0.473)$ & $0.571)$ \\
\hline \multirow{2}{*}{$\mathrm{A} 2$} & $(0.042$, & $(0.258$, & $(0.156$, & $(0.179$, \\
& $0.942)$ & $0.636)$ & $0.789)$ & $0.762)$ \\
\hline \multirow{2}{*}{$\mathrm{A} 3$} & $(0.042$, & $(0.449$, & $(0.239$, & $(0.179$, \\
& $0.942)$ & $0.441)$ & $0.661)$ & $0.762)$ \\
\hline \multirow{2}{*}{ A4 } & $(0.042$, & $(0.258$, & $(0.156$, & $(0.094$, \\
& $0.942)$ & $0.636)$ & $0.789)$ & $0.861)$ \\
\hline
\end{tabular}

(4) The intuitionistic fuzzy positive ideal scheme $\varphi^{+}$ and the intuitionistic fuzzy negative ideal scheme $\varphi^{-}$can be determined by (10)-(15). The calculation result is:

$$
\begin{aligned}
& \phi^{+}=\{(0.005,0.833)(0.116,0.281) \\
&(0.101,0.313)(0.077,0.436)\} \\
& \phi^{-}=\{(0.002,0.888)(0.067,0.405) \\
& \\
&(0.024,0.624)(0.017,0.656)\}
\end{aligned}
$$

(5) In (16)-(17), $\boldsymbol{d}_{j}^{+}$and $\boldsymbol{d}_{j}^{-}$are calculated. Where, $\boldsymbol{d}_{j}^{+}$ is the distance between the scheme $\boldsymbol{A}_{\boldsymbol{j}}$ and the intuitionistic fuzzy positive ideal scheme $\varphi^{+}$and $\boldsymbol{d}_{j}^{-}$is the distance between $\boldsymbol{A}_{j}$ and the intuitionistic fuzzy positive ideal scheme $\varphi^{+}$.

$$
\begin{aligned}
& d_{1}^{+}=0.232, d_{2}^{+}=0.252, d_{3}^{+}=0.226, d_{4}^{+}=0.267 \\
& d_{1}^{-}=0.240, d_{2}^{-}=0.149, d_{3}^{-}=0.173, d_{4}^{-}=0.153
\end{aligned}
$$

(6) According to formula (18), the intimacy coefficient $\boldsymbol{C} \boldsymbol{C}_{\boldsymbol{j}}$ of the intuitionistic fuzzy positive ideal solution distance $\boldsymbol{d}_{j}^{+}$and the intuitionistic fuzzy negative ideal solution distance $\boldsymbol{d}_{\boldsymbol{j}}^{-}$of every option are calculated. Sort the candidate schemes according to the intimacy coefficient. The evaluation results are shown in Table 5 . As can be seen from the analysis in Table 5, Alternative $\boldsymbol{A}_{\boldsymbol{I}}$ is the optimal solution.

Table 5. Evaluation result

\begin{tabular}{|c|c|c|}
\hline Options & Intimacy coefficient $C C$ & Rank \\
\hline A1 & 0.508 & 1 \\
\hline A2 & 0.372 & 3 \\
\hline A3 & 0.433 & 2 \\
\hline A4 & 0.364 & 4 \\
\hline
\end{tabular}

It can be seen from the analysis of the example that fuzzy multi-attribute decision making method is an intelligent decision-making method that relies on expert experience. It can make full use of fuzzy information to give the advantages and disadvantages of different energy alternative evaluation in multidimensional quickly and accurately. It solves the problem that the decision makers are difficult to complete the overall comprehensive evaluation when comparing and selecting multiple programs, and avoid the inaccurate evaluation results when the decision makers are focus on a certain attribute and it has certain evaluation impartiality.

\section{Conclusion}

Since the photovoltaic hybrid energy system alternative evaluation is ambiguous and involves many contradictory attributes, the quantitative evaluation of energy alternatives is very difficult. A fuzzy multi-attribute decision making method is designed. The intuitionistic fuzzy entropy is used to determine each attribute weight and direct fuzzy decision matrix, and to calculate the fuzzy normalized Euclidean distance between each scheme. The positive and negative ideal scheme is given by comparing the advantages and disadvantages of the evaluation program according to the intimacy coefficient CC. The simulation results show that the fuzzy multiattribute decision making method can effectively deal with the energy alternative evaluation. This method is feasible and practical.

\section{Acknowledgments}

This work is supported by State Grid Technology Program "Research and Demonstration of Key Technologies of 'Generation-Storage-Load' Coordinative Operation in Commercial Districts"(52094016000F).

\section{References}

1. Liao $\mathrm{H} \mathrm{C}, \mathrm{Xu} \mathrm{Z} \mathrm{S}$, Hesitant fuzzy decision making methodologies and applications (Springer, 2017)

2. Bo C, Guo Y Y, Gao X, Wang Y M, IEEE Access, 6, 55838. (2018)

3. Luo X, Li W M, Wang X Z, Zhao Z C, Journal of Systems Engineering and Electronics, 29, 1237. (2018)

4. Liu C F, Luo Y S, IEEE/CAA Journal of Automatica Sinica, 6, 575.(2019) 